\title{
Like a virgin (mother): analysis of data from a longitudinal, US population representative sample survey \\ (C) $(1)(9)$ OPEN ACCESS
}

\author{
Amy H Herring professor ${ }^{12}$, Samantha M Attard PhD candidate $^{23}$, Penny Gordon-Larsen professor ${ }^{23}$, \\ William $\mathrm{H}$ Joyner the reverend ${ }^{4}$, Carolyn $\mathrm{T}$ Halpern professor $^{25}$
}

'Department of Biostatistics, Gillings School of Global Public Health, University of North Carolina at Chapel Hill, CB 7420, Chapel Hill, NC 27599, USA; ${ }^{2}$ Carolina Population Center, Chapel Hill, NC, USA; ${ }^{3}$ Department of Nutrition, Gillings School of Global Public Health and School of Medicine, NC, USA; ${ }^{4}$ The Chapel of the Cross, Chapel Hill, NC, USA; ${ }^{5}$ Department of Maternal and Child Health, Gillings School of Global Public Health, NC, USA

\begin{abstract}
Objective To estimate the incidence of self report of pregnancy without sexual intercourse (virgin pregnancy) and factors related to such reporting, in a population representative group of US adolescents and young adults.

Design Longitudinal, population representative sample survey.

Setting Nationally representative, multiethnic National Longitudinal Study of Adolescent Health, United States.

Participants 7870 women enrolled at wave I (1995) and completing the most recent wave of data collection (wave IV; 2008-09).

Main outcome measures Self reports of pregnancy and birth without sexual intercourse.

Results 45 women $(0.5 \%)$ reported at least one virgin pregnancy unrelated to the use of assisted reproductive technology. Although it was rare for dates of sexual initiation and pregnancy consistent with virgin pregnancy to be reported, it was more common among women who signed chastity pledges or whose parents indicated lower levels of communication with their children about sex and birth control.

Conclusions Around $0.5 \%$ of women consistently affirmed their status as virgins and did not use assisted reproductive technology, yet reported virgin births. Even with numerous enhancements and safeguards to optimize reporting accuracy, researchers may still face challenges in the collection and analysis of self reported data on potentially sensitive topics.
\end{abstract}

\section{Introduction}

During Advent, many recount the birth of Jesus to the Virgin Mary. ${ }^{1}$ Virgin births in non-humans are generally by asexual reproduction, where growth and development of the embryo occurs without fertilization, termed parthenogenesis (from the Greek parthenos for virgin and genesis for birth). Occurrences of parthenogenesis in vertebrates, including pit vipers, boa constrictors, sharks, and Komodo dragons, ${ }^{2}$ have attracted much attention. Parthenogenesis also appears in popular culture, including the Spielberg blockbuster Jurassic Park ${ }^{3}$ and the 2008 Dr Who episode "Partners in Crime." ${ }^{4}$ Births without a human father are seen as distinct from asexual reproduction, and involve a non-mortal father - for example, the gospel of Matthew reports that Mary's was found to be "with child" from the Holy Spirit, and numerous Greek demigods, such as Perseus, were reportedly born of mortal women ${ }^{5}$ (or in the case of Dionysus, his immortal father, Zeus ${ }^{6}$ ).

Some supporters of the doctrine of the perpetual virginity (aeiparthenos) of Mary (who include not only Roman Catholics but also reformers such as Martin Luther) believe that Mary dedicated herself and her virginity to God, and that her husband Joseph was guardian of that virginity-perhaps a precursor of present day pledges of chastity. Chastity pledges may be signed by those who plan to remain chaste until marriage and by non-virgins who pledge to abstain from further intercourse until marriage; the latter are often called "born again" virgins"; this concept of the reconstitution of virginity has also appeared in pop culture, notably in the play Camino Real. ${ }^{8}$

Using data from the US nationally representative, multiethnic National Longitudinal Study of Adolescent Health (Add Health), spanning the 14 year lifecycle period between adolescence and adulthood, we examined the incidence of virgin pregnancy and birth based on self report of pregnancy and sexual debut, 
hypothesizing that individual and contextual factors may influence reporting.

\section{Methods \\ Data source}

Add Health began in 1994-95 as a representative sample of the US school aged population (grades 7-12, typically ages 12-18). A stratified sample of 132 schools was selected with probability of selection proportional to size. Add Health includes in-home, in-school, parent, and school administrator interviews, providing a wealth of sociodemographic, contextual, behavioral, and biological data. ${ }^{9}$ The in-home survey included 20745 youth in wave I (1994-95; mean age 15.7 years). All eligible school aged respondents were followed (including dropouts) in wave II (1996; mean age 16.2 years, response rate $88.6 \%$ ); all eligible wave I respondents were followed in waves III (2001; mean age 22.0 years, response rate $77.4 \%$ ) and wave IV (2007; mean age 28.5 years, response rate $80.3 \%$ ). State of the art technology (audio computer assisted self interview and computer assisted self interview) was used to enhance the candor of the respondents. We used sampling weights to account for the study design and dropout rate so that the results are generalizable to the US population.

\section{Inclusion criteria}

We included women enrolled in the main study who completed interviews at waves I and IV $(n=7870$, figure $\Downarrow)$.

\section{Dependent variable measurement and definition}

At every wave, participants reported their history of vaginal intercourse (defined as a male inserting his penis in a woman's vagina) and women reported their pregnancy history. We used these longitudinal data to classify women by their virginity status at the time of reported pregnancy. We defined virginity as consistent reporting of no history of vaginal intercourse. Women were classified as having virgin pregnancies if they reported a pregnancy before sexual debut. We classified the other women as non-virgins.

\section{Independent variable measurement and definition}

Unless indicated otherwise, all independent variables are from baseline (wave I).

Respondent reported variables included age, importance of religion, and presence of a chastity pledge. Respondents indicated how much they agreed with the following statements about contraception: you are quite knowledgeable about how to use a condom correctly; you are quite knowledgeable about the rhythm method of birth control and when it is a "safe" time during the month for a woman to have sex and not get pregnant; and you are quite knowledgeable about the withdrawal method of birth control.

Parents of respondents reported how much they had talked with their child about sex or birth control and indicated their level of agreement with the following statements: parent feels (s)he does not know enough to discuss sex/birth control with child; parent would find it difficult to discuss sex/birth control with child; parent feels child would be embarrassed by discussion of sex/birth control with parent.

School administrators reported whether sex education was offered in the respondent's school.
At waves I and IV, interviewers reported the quality of the interview, including number of interruptions, boredom of the respondent, and whether the respondent needed help with the questionnaire.

\section{Statistical analysis}

All analyses were conducted in Stata 12 and in Stat Xact (Cytel Studio 10.0, Cytel Software, Cambridge, MA). Using sampling weights to adjust for non-response and the study design, we computed the percentage of women in each group. We tested differences using Fisher's exact test for categorical variables and analysis of variance or Kruskal-Wallis tests for continuous variables. All differences presented are bivariate, without adjustment for potential confounders. We chose a significance level of 0.05 for groupwise tests; if significance was found, we used a step-down testing strategy to determine which individual differences were significant, to help preserve the type I error rate. ${ }^{10}$

\section{Results}

Of 7870 eligible women, 5340 reported a pregnancy, of whom 45 ( $0.8 \%$ of pregnant women) reported a virgin pregnancy (table $1 \Downarrow)$. Perceived importance of religion was associated with virginity but not with virgin pregnancy. The prevalence of abstinence pledges was $15.5 \%$. The virgins who reported pregnancies were more likely to have pledged chastity $(30.5 \%)$ than the non-virgins who reported pregnancies $(15.0 \%, \mathrm{P}=0.01)$ or the other virgins $(21.2 \%, \mathrm{P}=0.007)$.

The virgins who reported pregnancy were more likely to endorse knowledge of condom use (67.8\% agree/strongly agree) or the withdrawal method (53.6\% agree/strongly agree) than the other virgins $(30.2 \%, \mathrm{P}=0.007$ and $45.3 \%, \mathrm{P}=0.02$, respectively) but were less likely to know how to use condoms than the non-virgins who reported pregnancy $(79.6 \%, \mathrm{P}=0.002)$.

Parental attitudes and guidance were informative (table $2 \Downarrow$ ), with the parents of virgins who reported pregnancy more likely to indicate inadequate knowledge to discuss sex/birth control (27.7\% agree/strongly agree) than the parents of the other virgins $(1.7 \%, \mathrm{P}<0.001)$ or of the non-virgins with or without pregnancies $(5.2 \%$ and $3.9 \%, \mathrm{P}<0.001)$. The parents of virgins who reported pregnancy were more likely to strongly agree it was difficult to discuss sex/birth control with the child (12.2\%) than the parents of the virgins not reporting pregnancies $(<0.1 \%$, $\mathrm{P}<0.001)$ or of the non-virgins $(1.4 \%, \mathrm{P}=0.02)$. The parents of the virgins were more likely to strongly agree that their child would be embarrassed by these discussions $(11.5 \%)$ than the parents of the non-virgins with or without pregnancies $(2.3 \%$, $\mathrm{P}=0.002$ and $2.5 \%, \mathrm{P}=0.004)$. The frequency of discussions about sex was related to pregnancy but not to virginity.

Differences in the quality of the interviews were apparent (table $3 \Downarrow)$ but related to pregnancy rather than to virginity, with the exception of needing help with the questionnaire, which was more common among the virgins $(30.2 \%)$ than the non-virgins (10.8\%, $\mathrm{P}=0.007)$.

While more virgins gave birth to boys $(59.8 \%)$ or may have learnt they were pregnant during Advent, these trends did not reach statistical significance (table $4 \Downarrow$ ). Virgins were younger on average at the time of the birth (median age 19.3 years) than non-virgins (21.7 years, $\mathrm{P}<0.001)$.

\section{Discussion}

We examined the incidence of self reports consistent with virgin pregnancy in the US nationally representative, multiethnic 
National Longitudinal Study of Adolescent Health (Add Health). Reporting dates of pregnancy and sexual initiation consistent with virgin pregnancy was associated with cultural mores highly valuing virginity, specifically signing chastity pledges, and with parental endorsement of items indicative of lower levels of communication about sex and birth control

\section{Limitations and strengths of this study}

While most pregnancies occurred in adulthood, some participants may have misunderstood the definition of sexual intercourse. In a study of Canadian college students, $90 \%$ considered penile vaginal intercourse with orgasm as "having sex." ${ }^{11}$ Questions in Add Health regarding sex were clear, limiting the risk of misinterpretation.

Errors in data entry are possible. However, among "virgin pregnancies," the median sexual debut reported was 2 (interquartile range 1-6) years after the pregnancy, and numerous women reported virginity at multiple subsequent waves. While Add Health collected information about use of assisted reproductive technologies, all the virgins who reported pregnancies stated that they did not conceive by such methods.

One study ${ }^{12}$ examined demographic and health survey data from Africa and noted that data problems arose from both recall errors and misinterpretation of sexual debut as the age at onset of intercourse with husbands. Because Add Health obtains data on sexual history before data on pregnancy, this type of misinterpretation is unlikely, though recall bias is possible. We note that the African study incorrectly refers to virgin births as immaculate conceptions. The doctrine of the immaculate conception of Mary, often confused with virgin birth, is that though Mary was conceived in the normal way, she was without the stain of original sin.

A third group of women $(\mathrm{n}=244)$ not included in analysis, "born again virgins," reported a history of sexual intercourse early in the study but later provided a conflicting report indicating virginity. Reports of pregnancy among born again virgins were associated with greater knowledge of contraception methods with higher failure rates (withdrawal and rhythm methods) and lower interview quality (data not shown), and reports from this group may be subject to greater misclassification error.

Numerous important factors can be only feasibly or affordably measured in large samples using self report in surveys, including sexual history, illicit drug use, domestic violence, maltreatment as a child, and diet. Unfortunately this means there is no ideal against which to judge accuracy of self report. Self reported sexual behavior is often "validated" through consistency analyses, wherein respondents' answers to the same questions at multiple time points are compared. Analyses of age at first vaginal sex suggest that $80-90 \%$ of respondents report a consistent age, with repeated measures crossing months ${ }^{13}{ }^{14}$ or even years. $^{15}$

Even assuming all the self reports of virgin pregnancies in Add Health are due to error, the misclassification rate is low. In a randomized experiment, researchers ${ }^{16}$ found that respondents who used audio computer assisted self interview were 1.46 times more likely to acknowledge that they had oral sex than respondents who used computer assisted personal interview and reported their behavior directly to an interviewer. The difference was even larger for an illegal behavior: respondents who used audio computer assisted self interview were 2.84 times more likely to acknowledge that they had used cocaine than respondents who used computer assisted personal interview. The use of audio computer assisted self interview in wave I and computer assisted self interview in waves III and IV of Add
Health almost surely enhanced the candor of respondents when answering potentially sensitive questions.

\section{Conclusion}

All self reported measures of potentially sensitive items are subject to some degree of respondent bias, especially in studies that, unlike Add Health, do not use confidential reporting. In a US nationally representative cohort, we found that $0.8 \%$ of pregnancies were reported by virgins and not related to use of assisted reproductive technology, and these women were more likely than other virgins to have signed chastity pledges, to endorse knowledge of birth control, and to have parents who endorsed items indicative of lower levels of communication about sex and birth control.

We thank Abigail Haydon for the title idea and Mariah Chang for assistance with variable construction. PG-L thanks Rabbi Arnold Mark Belzer, DD, president of the Sino-Judaic Institute, for his advice on the role of virgin birth in Judaism. The STROBE statement (www.strobestatement.org) was used to guide analysis and presentation of results. This research uses data from Add Health, a program project directed by Kathleen Mullan Harris and designed by J Richard Udry, Peter S Bearman, and Kathleen Mullan Harris at the University of North Carolina at Chapel Hill, and funded by grant P01-HD31921 from the Eunice Kennedy Shriver National Institute of Child Health and Human Development, with cooperative funding from 23 other federal agencies and foundations. We thank Ronald R Rindfuss and Barbara Entwisle for assistance in the original design. Information on how to obtain the Add Health data files is available on the Add Health website (www.cpc. unc.edu/addhealth).

Contributors: AHH, CTH, and PG-L set forth the original hypotheses of interest. SA and $\mathrm{AHH}$ conducted the statistical analysis. $\mathrm{AHH}$ and $\mathrm{SA}$ drafted the manuscript, and all authors critically revised the manuscript and provided important intellectual content. AHH, CTH, and PG-L, the guarantors, affirm that this manuscript is an honest, accurate, and transparent account of the study being reported; that no important aspects of the study have been omitted; and that any discrepancies from the study as planned (and, if relevant, registered) have been explained. All authors had full access to the statistical reports and tables in the study and can take responsibility for the integrity of the data and accuracy of its analysis.

Funding: No direct support was received from grant P01-HD31921 for this analysis. AHH and CTH were supported by grant R01-HD57046, and PG-L and SMA by grant R01-HD057194, from the Eunice Kennedy Shriver National Institute of Child Health and Human Development. The Carolina Population Center (R24 HD050924) provided general support. Competing interests: All authors have completed the ICMJE uniform disclosure form at www.icmje.org/coi_disclosure.pdf and declare: no support from any organisation for the submitted work; no financial relationships with any organisations that might have an interest in the submitted work in the previous three years; no other relationships or activities that could appear to have influenced the submitted work.

Ethical approval: Our institutional review board application for the protection of human participants was declared exempt owing to deidentified data and an approved data security plan that minimizes the risk of deductive disclosure (study No 09-0570). Original data collection was approved by the institutional review board at the University of North Carolina at Chapel Hill. Present analyses were deemed exempt.

Data sharing: The Add Health data are publicly available by request at www.cpc.unc.edu/projects/addhealth/data/publicdata and www.cpc.unc. edu/projects/addhealth/data/restricteduse. The authors of this manuscript are not authorized to provide data directly to any users.

Matthew 1:18-25, Luke 1:26-38. Holy Bible (authorized (King James) version). Robert Barker, Printer to the King's Most Excellent Majestie, 1611 


\section{What is already known on this topic}

Among humans the incidence of self reported dates of sexual debut and pregnancy consistent with virgin pregnancy is unknown

\section{What this study adds}

In a large survey representative of the US population, around $0.5 \%$ of women consistently affirmed their status as virgins and did not use assisted reproductive technology, yet reported virgin births

The study used carefully designed questions and state of the art self interview technology known to enhance the candor of respondents utmb.edu/newsroom/article8559.aspx

3 Kennedy K, Molen GR (producers), Spielberg S (director). 11 June 1993. Jurassic Park [motion picture]. Amblin Entertainment.

4 Partners in crime. Dr Who BBC 1, 5 April 2008.

Homer, lliad, $14.319 \mathrm{ff}$ (trans Lattimore).

Euripides, Bacchae, $520 \mathrm{ff}$.

Born-again virgin. http://en.wikipedia.org/wiki/Born-again_virgin

Williams TL. Camino Real . New Directions, 1953.

9 Harris KM, Halpern CT, Whitsel E, Hussey J, Tabor J, Entzel P, et al. The National Longitudinal Study of Adolescent Health: research design. 2009. www. cPc unc edu/ projects/addhealth/design

10 Muller KE, Fetterman BA. Regression and ANOVA: an integrated approach using SAS Software. SAS Publishing, 2002

11 Byers ES, Henderson J, Hobson KM. University students' definitions of sexual abstinence and having sex. Arch Sex Behav 2009;38:665-74.

12 Meekers D. Immaculate conceptions in sub-Saharan Africa: exploratory analysis of inconsistencies in timing of first sexual intercourse and first birth. Soc Biol 1995;42:151-61.
13 Dunne MP. The consistency of recalled age at first sexual intercourse. J Biosoc Sci 1997;29:1-7.

14 Rohan TE. Repeatability of interview-derived information on sexual history: a study in women. Epidemiology 1994;5:360

15 Goldberg S, Haydon AA, Herring AH, Halpern CT. Longitudinal consistency in self-reported age at first vaginal intercourse among young adults. J Sex Res 2012; published online 13 Dec. DOI:10.1080/00224499.2012.719169.

16 Tourangeau R, Smith TW. Asking sensitive questions: the impact of data collection, mode, question format, and question context. Public Opin Quart 1996;60:275-304.

\section{Cite this as: BMJ 2013:347:f7102}

This is an Open Access article distributed in accordance with the Creative Commons Attribution Non Commercial (CC BY-NC 3.0) license, which permits others to distribute, remix, adapt, build upon this work non-commercially, and license their derivative works on different terms, provided the original work is properly cited and the use is non-commercial. See: http://creativecommons.org/licenses/by-nc/3.0/. 


\section{Tables}

Table 1 | Characteristics of women according to status of their virginity, from National Longitudinal Study of Adolescent Health. Values are numbers (percentages) unless stated otherwise

\begin{tabular}{|c|c|c|c|c|}
\hline \multirow[b]{2}{*}{ Characteristics } & \multicolumn{2}{|c|}{ Virgins } & \multicolumn{2}{|c|}{ Non-virgins } \\
\hline & No pregnancy & Pregnancy & No pregnancy & Pregnancy \\
\hline Women & $146(2.5)$ & $45(0.5)$ & $2319(30.7)$ & $5116(63.8)$ \\
\hline Mean (SE) age at wave I & $14.9(0.5)$ & $14.4(0.4)$ & $14.4(0.1)$ & $14.8(0.1)$ \\
\hline \multicolumn{5}{|c|}{ Importance of religion at wave $I^{\star \star *}$ : } \\
\hline Very important & $91(49.0)$ & $24(53.3)$ & $1017(43.4)$ & $2330(42.7)$ \\
\hline Somewhat important & $30(19.5)$ & $11(22.7)$ & $800(33.5)$ & $1750(35.5)$ \\
\hline Somewhat unimportant & $5(2.6)$ & $-(7.9)$ & $163(7.7)$ & $257(5.4)$ \\
\hline Very unimportant & $3(8.4)$ & $-(<0.1)$ & $69(3.0)$ & $114(2.4)$ \\
\hline Refused/don't know & $17(20.5)$ & $7(16.2)$ & $270(12.4)$ & $665(14.0)$ \\
\hline \multicolumn{5}{|c|}{ Sex education offered in school: } \\
\hline No & $25(11.6)$ & $8(21.4)$ & $321(12.6)$ & $806(16.2)$ \\
\hline Yes & $114(84.6)$ & $35(73.9)$ & $1869(79.8)$ & $4089(78.0)$ \\
\hline Missing & $7(3.8)$ & $2(4.6)$ & $129(7.6)$ & $221(5.8)$ \\
\hline \multicolumn{5}{|c|}{$\begin{array}{l}\text { Took pledge to remain virgin until } \\
\text { married, wave }\left.\right|^{\star \star *} \text { : }\end{array}$} \\
\hline No & $100(72.4)$ & $31(66.4)$ & $1888(82.5)$ & $4256(83.7)$ \\
\hline Yes & $40(21.2)$ & $12(30.5)$ & $410(16.4)$ & $801(15.0)$ \\
\hline Missing/refused & $6(6.4)$ & $2(3.1)$ & $21(1.1)$ & $59(1.3)$ \\
\hline \multicolumn{5}{|l|}{ Respondent beliefs } \\
\hline \multicolumn{5}{|c|}{$\begin{array}{l}\text { Knows how to use a condom correctly, } \\
\text { wave } I^{\star * *} \text { : }\end{array}$} \\
\hline Strongly agree & $22(14.3)$ & $10(16.1)$ & $686(29.1)$ & $2103(41.3)$ \\
\hline Agree & $43(15.9)$ & $19(51.7)$ & $902(37.6)$ & $1996(38.3)$ \\
\hline Neither agree nor disagree & $26(15.1)$ & $5(8.2)$ & $313(12.7)$ & $426(8.5)$ \\
\hline Disagree & $22(18.2)$ & $5(16.0)$ & $228(9.8)$ & $321(5.9)$ \\
\hline Strongly disagree & $13(5.7)$ & $3(0.6)$ & $113(5.1)$ & $145(2.9)$ \\
\hline Don't know/refused & $20(30.8)$ & $3(7.3)$ & $77(5.8)$ & $125(3.1)$ \\
\hline \multicolumn{5}{|c|}{$\begin{array}{l}\text { Knows how to use rhythm method of } \\
\text { contraception, wave } I^{\star \star *} \text { : }\end{array}$} \\
\hline Strongly agree & $13(6.5)$ & $6(14.4)$ & $329(13.9)$ & $1007(19.0)$ \\
\hline Agree & $38(13.6)$ & $16(39.6)$ & $760(31.3)$ & $1927(37.3)$ \\
\hline Neither agree nor disagree & $34(19.2)$ & $7(16.5)$ & $478(20.0)$ & $938(19.3)$ \\
\hline Disagree & $27(17.7)$ & $10(19.6)$ & $478(20.6)$ & $788(15.1)$ \\
\hline Strongly disagree & $14(7.2)$ & $3(2.5)$ & $163(6.6)$ & $276(5.1)$ \\
\hline Don't know/refused & $20(35.7)$ & $3(7.3)$ & $111(7.4)$ & $180(4.2)$ \\
\hline \multicolumn{5}{|c|}{$\begin{array}{l}\text { Knows how to use withdrawal method } \\
\text { of contraception, wave } \mathrm{I}^{\star \star *} \text { : }\end{array}$} \\
\hline Strongly agree & $14(8.6)$ & $7(12.3)$ & $356(15.1)$ & $1077(20.5)$ \\
\hline Agree & $29(12.7)$ & $19(43.1)$ & $869(35.3)$ & $2271(44.1)$ \\
\hline Neither agree nor disagree & $41(23.3)$ & $9(22.8)$ & $468(20.2)$ & $843(16.8)$ \\
\hline Disagree & $29(14.1)$ & $5(8.6)$ & $377(16.1)$ & $583(11.1)$ \\
\hline Strongly disagree & $11(6.1)$ & $-(6.0)$ & $125(5.3)$ & $158(3.2)$ \\
\hline Don't know/refused & $22(35.3)$ & $-(7.3)$ & $124(8.1)$ & $184(4.3)$ \\
\hline
\end{tabular}

Percentages calculated using survey weights to allow population representative inference. Dash indicates cell size was too small to be displayed. Data from 244 "born again virgins" who reported sex in an early wave but later recanted are not shown.

${ }^{* *} \mathrm{P}<0.001$ using analysis of variance for continuous variables and Fisher's exact test for categorical variables. 
Table 2| Parental attitudes and guidance according to respondent's virginity status and gravidity, from National Longitudinal Study of Adolescent Health, wave I. Values are numbers (percentages)

\begin{tabular}{|c|c|c|c|c|}
\hline \multirow[b]{2}{*}{ Variables } & \multicolumn{2}{|c|}{ Virgins } & \multicolumn{2}{|c|}{ Non-virgins } \\
\hline & No pregnancy & Pregnancy & No pregnancy & Pregnancy \\
\hline Women & $146(2.5)$ & $45(0.5)$ & $2319(30.7)$ & $5116(63.8)$ \\
\hline \multicolumn{5}{|c|}{$\begin{array}{l}\text { Parent feels (s)he does not know enough } \\
\text { to discuss sex/birth control with child }{ }^{\star \star \star} \text { : }\end{array}$} \\
\hline Strongly agree & $3(0.5)$ & $4(11.9)$ & $35(1.1)$ & $104(2.1)$ \\
\hline Agree & $4(1.2)$ & $5(11.3)$ & $79(2.8)$ & $195(3.1)$ \\
\hline Neither agree nor disagree & $6(5.6)$ & $5(9.7)$ & $78(3.3)$ & $197(3.7)$ \\
\hline Disagree & $41(43.4)$ & $14(23.8)$ & $721(32.0)$ & 1605 (31.5) \\
\hline Strongly disagree & $76(43.2)$ & $10(26.9)$ & $1136(51.7)$ & $2239(46.0)$ \\
\hline Don't know/refused/missing & $16(6.0)$ & $7(16.4)$ & $270(9.1)$ & $776(13.6)$ \\
\hline \multicolumn{5}{|c|}{$\begin{array}{l}\text { Parent would find it difficult to discuss } \\
\text { sex/birth control with child }{ }^{*} \text { : }\end{array}$} \\
\hline Strongly agree & $-(<0.1)$ & $5(12.2)$ & $27(1.0)$ & $73(1.4)$ \\
\hline Agree & $8(9.1)$ & $-(5.5)$ & $129(7.2)$ & $246(4.2)$ \\
\hline Neither agree nor disagree & $-(4.0)$ & $-(4.8)$ & $91(4.2)$ & $172(3.1)$ \\
\hline Disagree & $58(42.0)$ & $16(25.8)$ & $870(37.8)$ & $1859(37.1)$ \\
\hline Strongly disagree & $60(38.3)$ & $12(35.3)$ & $934(40.9)$ & $1985(40.6)$ \\
\hline Don't know/refused/missing & $17(6.5)$ & $7(16.4)$ & $268(9.0)$ & $781(13.7)$ \\
\hline \multicolumn{5}{|c|}{$\begin{array}{l}\text { Parent feels child would be embarrassed } \\
\text { if parent discussed sex/birth control with } \\
\text { them }{ }^{\star \star *} \text { : }\end{array}$} \\
\hline Strongly agree & $3(2.4)$ & $5(11.5)$ & $53(2.5)$ & $120(2.3)$ \\
\hline Agree & $19(27.8)$ & $3(5.8)$ & $334(14.7)$ & $566(11.1)$ \\
\hline Neither agree nor disagree & $8(6.1)$ & $3(10.7)$ & $200(9.6)$ & $322(6.7)$ \\
\hline Disagree & $54(32.3)$ & $16(28.2)$ & $809(34.9)$ & $1703(33.0)$ \\
\hline Strongly disagree & $45(25.1)$ & $11(27.5)$ & $656(29.3)$ & $1622(33.1)$ \\
\hline Don't know/refused/missing & $17(6.3)$ & $7(16.4)$ & $267(9.0)$ & $783(13.7)$ \\
\hline \multicolumn{5}{|c|}{$\begin{array}{l}\text { How much has the parent talked with the } \\
\text { child about sex?***: }\end{array}$} \\
\hline Not at all & $11(11.2)$ & $5(15.5)$ & $134(6.6)$ & $248(4.9)$ \\
\hline Somewhat & $36(23.1)$ & $7(15.0)$ & $512(24.4)$ & $752(14.5)$ \\
\hline A moderate amount & $50(33.0)$ & $12(16.3)$ & $775(32.9)$ & $1366(27.7)$ \\
\hline A great deal & $32(26.5)$ & $14(36.7)$ & $613(26.3)$ & $1933(38.3)$ \\
\hline Don't know/refused/missing & $17(6.1)$ & $7(16.4)$ & $285(9.8)$ & $817(14.5)$ \\
\hline
\end{tabular}

Percentages calculated using survey weights to allow population representative inference. Dash indicates cell size was too small to be displayed. Data from 244 "born again virgins" who reported sex in an early wave but later recanted are not shown.

${ }^{*} \mathrm{P}<0.05$.

${ }^{* \star *} \mathrm{P}<0.001$ using ANOVA for continuous variables and Fisher's exact test for categorical variables. 
Table 3 | Interview quality at waves I and IV according to virginity status, from National Longitudinal Study of Adolescent Health. Values are numbers (percentages) unless stated otherwise

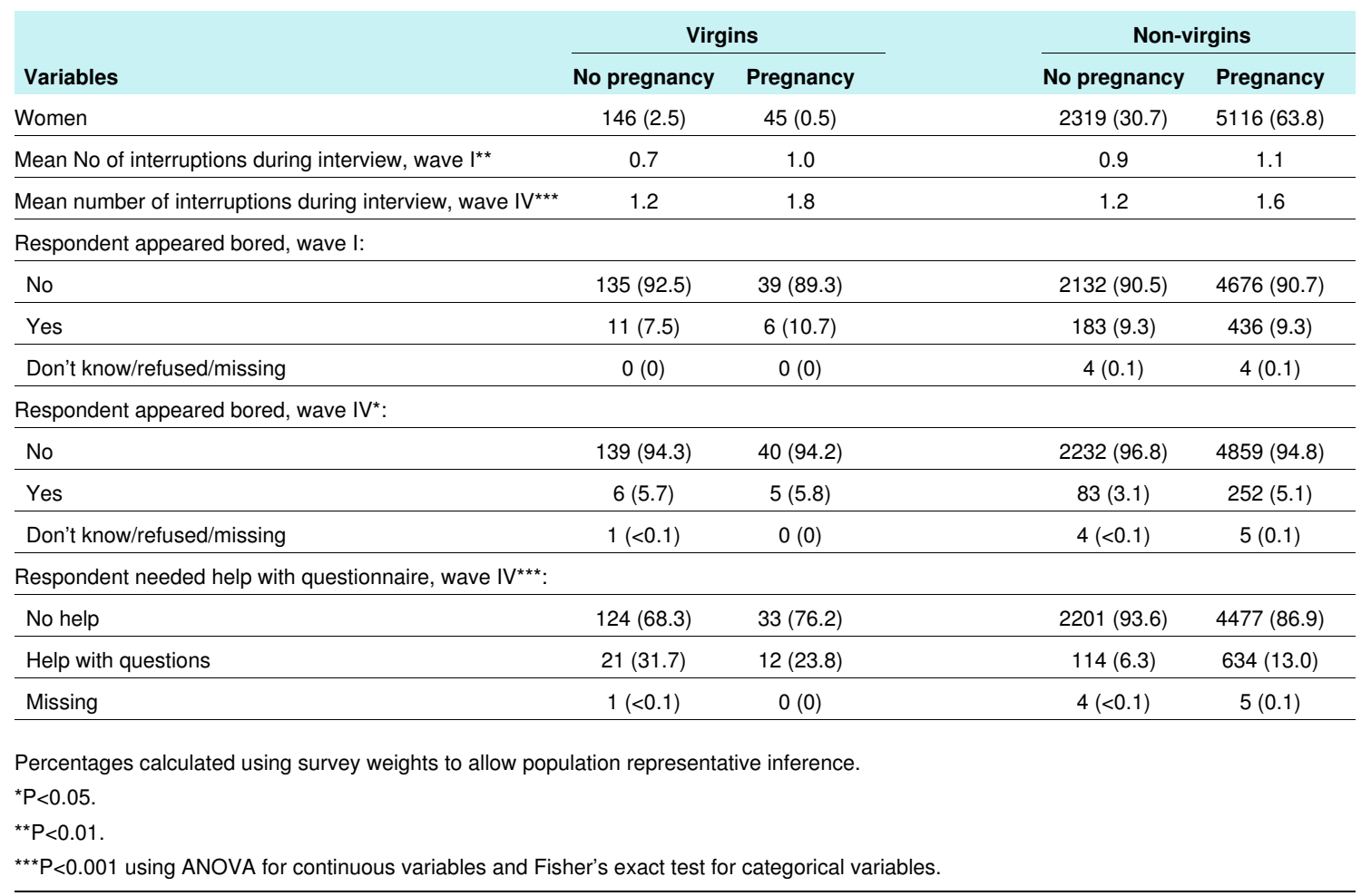


Table 4 | Characteristics of first live births according to virginity status, from National Longitudinal Study of Adolescent Health. Data are numbers (percentages) unless stated otherwise

\begin{tabular}{|c|c|c|}
\hline Characteristics & Virgins & Non-virgins \\
\hline \multicolumn{3}{|l|}{ Baby's sex: } \\
\hline Boy & $20(59.8)$ & 2114 (52.2) \\
\hline Girl & $16(40.2)$ & $2063(47.6)$ \\
\hline \multicolumn{3}{|l|}{ Season of birth*: } \\
\hline Spring & $4(8.2)$ & $1035(24.8)$ \\
\hline Summer & $15(48.2)$ & $1081(24.8)$ \\
\hline Fall & $8(12.8)$ & $1035(24.4)$ \\
\hline Winter & $9(30.8)$ & $1031(26.0)$ \\
\hline $\begin{array}{l}\text { Percentages calculated using survey weights to allow population } \\
\text { *Spring (March-May), summer (June-August), fall (September-No }\end{array}$ & $\begin{array}{l}\text { ative inference. } \\
\text { winter (December-Fe }\end{array}$ & \\
\hline \multicolumn{3}{|c|}{${ }^{* \star *} \mathrm{P}<0.001$ using Kruskal-Wallis test of medians for continuous variables and Fisher's exact test for categorical variables. } \\
\hline
\end{tabular}




\section{Figure}

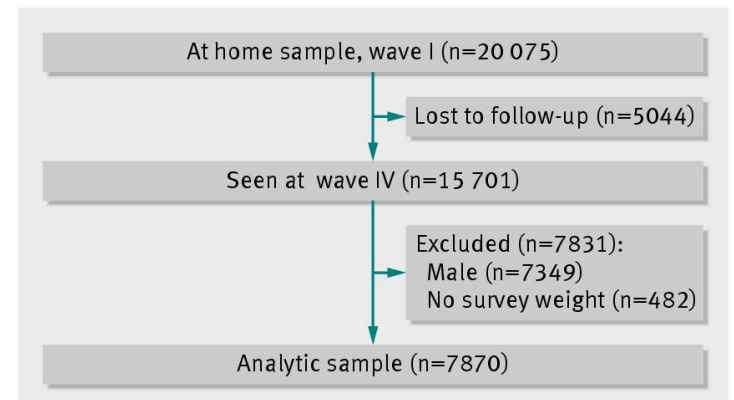

Study population and sample attrition. Women without a survey weight were added to enrich the sample for specific hypotheses (for example, twin or sibling studies) and are not considered part of the core representative sample or women over-sampled by design 